\title{
Ionic Liquid as Useful Media for Dissolution, Derivatization, and Nanomaterial Processing of Chitin
}

\author{
Jun-Ichi Kadokawa \\ Graduate School of Science and Engineering, Kagoshima University, Kagoshima, Japan \\ Email: kadokawa@eng.kagoshima-u.ac.jp
}

Received March 4, 2013; revised April 6, 2013; accepted April 15, 2013

Copyright (C) 2013 Jun-Ichi Kadokawa. This is an open access article distributed under the Creative Commons Attribution License, which permits unrestricted use, distribution, and reproduction in any medium, provided the original work is properly cited.

\begin{abstract}
This paper reviews studies on dissolution, derivatization, and nanomaterial processing of chitin using an ionic liquid as useful media. Because chitin is the second most abundant polysaccharide on the earth after cellulose, there is major interest in conversion of native chitin resources into various useful materials after proper dissolution in suitable solvents. For the derivatization and nanomaterial processing of chitin, the author has been focusing on ionic liquids because which have been found to be used as good solvents for cellulose in a past decade. The author found that an ionic liquid, 1-allyl-3-methylimidazolium bromide (AMIMBr), dissolved chitin in concentrations up to $4.8 \mathrm{wt} \%$ and mixtures of the higher amounts of chitin with AMIMBr gave ion gels. Acetylation, the simplest derivatization, of chitin using acetic anhydride was achieved in the AMIMBr solvent under mild conditions. Furthermore, the chitin nanofibers were fabricated by regeneration technique from the chitin ion gel with AMIMBr using methanol. Moreover, filtration of the chitin nanofiber dispersion with methanol was carried out to give a chitin nanofiber film. The chitin nanofiber-poly(vinyl alcohol) composite film was also prepared from the ion gel by co-regeneration method.
\end{abstract}

Keywords: Chitin; Ionic Liquid; Derivatization; Nanofiber; Composite Material

\section{Introduction}

Ionic liquids are low-melting-point molten salts, defined as that form liquids at room temperature or even at temperatures lower than the boiling point of water. The property is owing to that the liquid state is thermodynamically favorable due to the large size and conformational flexibility of the ions, in which these behaviors lead to small lattice enthalpies and large entropy changes that favor the liquid state $[1,2]$. In the past more than a decade, ionic liquids have attracted much attention due to their specific characteristics such as excellent thermal stabilities, a negligible vapor pressure, and controllable physical and chemical properties [3]. Beyond these traditional properties of ionic liquids, recently, interests and applications on ionic liquids have been extended to the researches related to biological macromolecules such as naturally occurring polysaccharides, because of specific good affinities of ionic liquids for them [4].

Polysaccharides are widely distributed in nature and have been regarded as structural materials and as suppliers of water and energy [5]. Of the many kinds of polysaccharides, cellulose and chitin are the most important biomass resources because they are the first and second most abundant natural polysaccharides on the earth, respectively [6-10]. Chitin is an aminopolysaccharide consisting of $\beta(1 \rightarrow 4)$-linked $N$-acetyl-D-glucosamine residues, which has acetamido groups at the $\mathrm{C}-2$ position in place of hydroxy groups of the glucose residues in cellulose (Figure 1). Despite its huge production in nature and easy accessibility, chitin still remains as an unutilized biomass resource primary because of its intractable bulk structure and insolubility in water and common organic solvents. Even in recent years, therefore, there is major interest in conversion into various useful materials after proper dissolution of chitin in suitable solvents.

Chitin occurs mainly in the exoskeletons of crustacean shells such as crab and shrimp shells in nature. Native chitin in crustacean shells is arranged as microfibrils embedded in a protein matrix $[11,12]$. The microfibril is composed of nanofibers with $2 \mathrm{~nm}-5 \mathrm{~nm}$ diameters. Moreover, three types of crystalline forms, i.e., $\alpha-, \beta$-, and $\gamma$-chitins, are known depending on the arrangement of the polymeric chains. The most abundant form is $\alpha$-chitin (e.g., from crab and shrimp shells) [13], where the polymeric chains are aligned in an antiparallel fashion. This arrangement is favorable for the formation of 


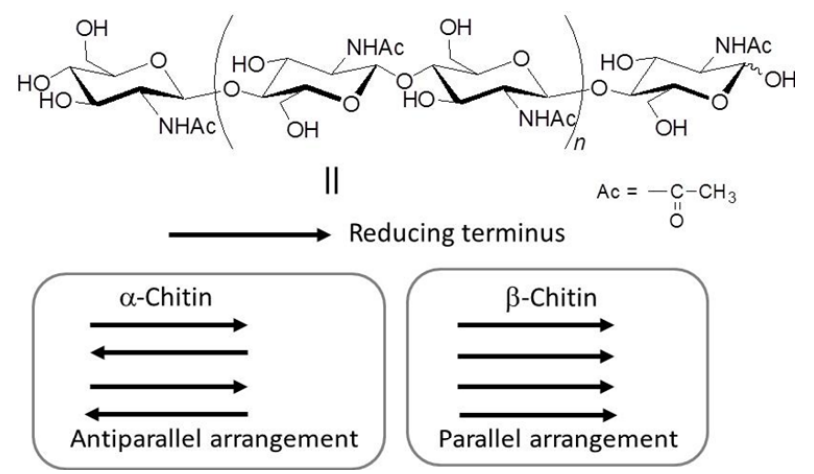

Figure 1. Chemical structure of chitin and schematic image of chitin crystalline structures.

strong intermolecular hydrogen bonding, leading to the most stable form in the three types of crystalline structures. In $\beta$-chitin (e.g., from squid pen), the polymeric chains are packed in a parallel arrangement [14], resulting in weaker intermolecular forces. Accordingly, $\beta$-chitin is considered to be less stable than $\alpha$-chitin. $\gamma$-Chitin may be a mixture of $\alpha$ - and $\beta$-forms.

Since Rogers et al. comprehensively reported that an ionic liquid, 1-butyl-3-methylimidazolium chloride, dissolved cellulose in relatively high concentrations [15], ionic liquids have began to be used in the processing of cellulose, which mainly concern with the dissolution, homogeneous derivatization and modification, and regeneration [16-19]. Therefore, ionic liquids are considered as powerful solvents and are used for material processing of cellulose. On the other hand, only the limited investigations have been reported regarding the dissolution of chitin with ionic liquids including the author's study, in which the author found that an ionic liquid, 1-allyl-3-methylimidazolium bromide (AMIMBr), dissolved or swelled chitin to form weak gel-like materials (ion gels) (Figure 2) [20,21]. The other groups have also reported the dissolution of chitin with ionic liquids, 1-butyl- and 1-ethyl-3-methylimidazolium acetates (Figure 2) $[22,23]$. However, the dissolution of chitin with other ionic liquids having different cationic, anionic, and substituent structures has hardly been reported. The observation suggests that the aforementioned ionic liquids only having specific structures probably exhibit a potential for the dissolution of chitin [24-27].

Chemical derivatization of chitin is one of the efficient approaches to explore their potentials, giving the novel types of functional materials $[28,29]$. Derivatization of chitin, however, is generally difficult owing to a lack of solubility as aforementioned, and thus the reactions often take place under heterogeneous conditions, leading to low degree of substitution (DS). Even acetylation of chitin, a simplest derivatization, has been performed only under special conditions. The author has considered that ionic liquids, that dissolve chitin, act as efficient media for derivatizations of chitin with high DS, and thus investigated acetylation of chitin in AMIMBr [30].

On the other hand, the preparation of self-assembled fibrillar nanostructures, so-called nanofibers, is one of the most useful methods to practically utilize polymeric functional materials from native chitin sources [31-33]. Conventional approaches to the production of chitin nanofibers are mainly performed upon top-down procedures that break down the starting bulk materials from native chitin sources (Figure 3). As the representative techniques, acid hydrolysis [34-37], 2,2,6,6-tetramethylpiperidine-1-oxyl radical (TEMPO)-mediated oxidation $[38,39]$, and grinding technique $[40,41]$ have previously been performed to produce chitin nanofibers from native chitin sources. The other method accorded to self-assembling generative (bottom-up) route (Figure 3), in which fibrillar nanostructures were produced by regeneration from chitin solutions via appropriate process, as examples of the electrospinning equipment $[42,43]$ and simple precipitation process $[44,45]$. To efficiently provide chitin nanofibers by the bottom-up technique, the author has focused on the ionic liquid, AMIMBr. Accordingly, the author successfully reported that chitin nanofiber films were facilely obtained by regeneration from the ion gels with AMIMBr using methanol, followed by filtration [46].

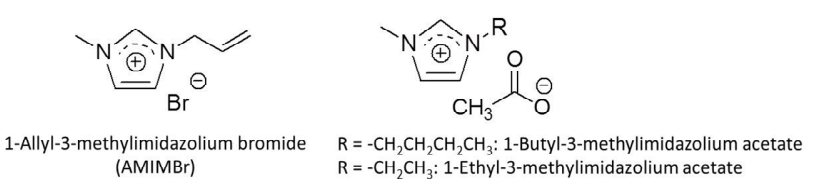

Figure 2. Representative ionic liquids that dissolve chitin.

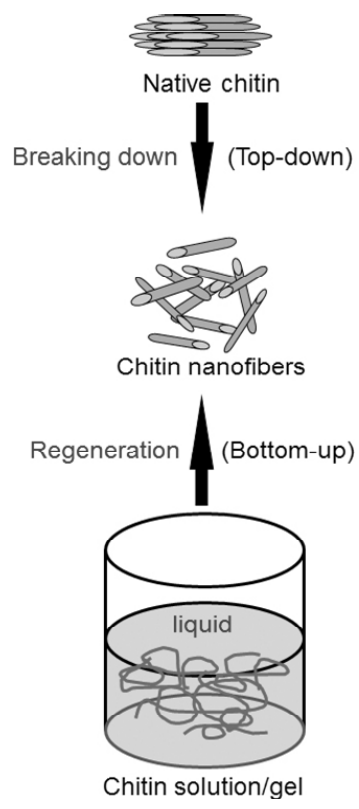

Figure 3. Top-down and bottom-up approaches for preparation of chitin nanofibers. 
On the basis of the above backgrounds and viewpoints, this paper reviews the studies on the dissolution, acetylation, and nanofibrillation using AMIMBr. The series of the studies provide new approaches for material processing from native chitin sources.

\section{Dissolution of Chitin with Ionic Liquid}

For the dissolution study of chitin with ionic liquids, the author noted the previous study reporting that the imidazolium-type ionic liquids having a bromide counter anion were the good solvents for synthesis of polyamides and polyimides [47]. The result inspired to use the same kind of ionic liquids for dissolution of chitin, because chitin has the $-\mathrm{N}-\mathrm{C}=\mathrm{O}$ groups as same as polyamides and polyimides. Thus, three ionic liquids consisting of a bromide anion were prepared, which were AMIMBr, 1-methyl-3propylimidazolium bromide, and 1-butyl-3-methylimidazolium bromide, and the dissolution experiments were conducted as follows [21].

A mixture of chitin with each ionic liquid was heated at $100^{\circ} \mathrm{C}$ and the heating process was simply followed by a charge coupled device (CCD) camera on glass plate. When AMIMBr was used for the dissolution experiment, the clear solutions of chitin were formed in the concentrations up to $\sim 4.8 \mathrm{wt} \%$ (Figure $4(\mathbf{a})$ ), whereas the other ionic liquids did not show ability to dissolve chitin even in $1 \mathrm{wt} \%$ concentration. The disappearance of chitin powder in the solution of $4.8 \mathrm{wt} \%$ chitin with AMIMBr was confirmed further by the SEM measurement. The SEM image of the mixture of chitin with AMIMBr after heating it at $100^{\circ} \mathrm{C}$ for $48 \mathrm{~h}$ did not show any solid of chitin (Figure 4(b)), suggesting that $4.8 \mathrm{wt} \%$ chitin was solvated with AMIMBr at least at the $\mu \mathrm{m}$ scale level.

It was confirmed as follows that degradation and decrease in the molecular weight of chitin did not frequently occur during dissolution with AMIMBr. The powder X-ray diffraction (XRD), thermal gravimetrical analysis (TGA), and IR results of the regenerated chitin from the solution with AMIMBr, which was prepared by addition of methanol into it, followed by filtration and dryness of the precipitate, were almost same as those of the original chitin. In addition, the hexanoyl derivative of the regenerated chitin, which was synthesized by the re-

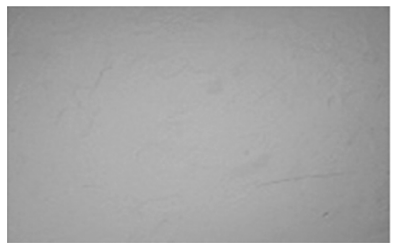

(a)

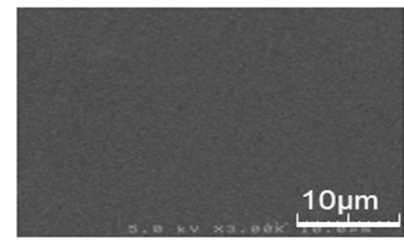

(b)
Figure 4. CCD camera view (a) and SEM image (b) of a mixture of chitin $(4.8 \mathrm{wt} \%)$ with AMIMBr after dissolution experiment $\left(100^{\circ} \mathrm{C}, 48 \mathrm{~h}\right)$. action of the regenerated material with hexanoyl chloride [48], showed the exact same ${ }^{1} \mathrm{H}$ NMR pattern as that of the hexanoylated sample from the original chitin and the GPC profiles of both the derivatives were not much different from each other.

Interestingly, mixtures of higher amounts of chitin with AMIMBr gave more viscous materials, i.e., gel-like materials when $6.5 \mathrm{wt} \%-10.7 \mathrm{wt} \%$ of chitin were immersed in AMIMBr at room temperature for $24 \mathrm{~h}$, followed by heating at $100^{\circ} \mathrm{C}$ for $48 \mathrm{~h}$ and cooling to room temperature. Indeed, the obtained $6.5 \mathrm{wt} \%$ chitin with AMIMBr did not flow upon leaning a test tube, whereas the aforementioned $4.8 \mathrm{wt} \%$ chitin with AMIMBr started to flow upon leaning (Figure 5). The dynamic rheological measurements showed that both $4.8 \mathrm{wt} \%$ and $6.5 \mathrm{wt} \%$ chitins with AMIMBr behaved as the weak gels.

\section{Acetylation of Chitin in Ionic Liquid}

As a simplest and useful derivatization reaction of chitin, acetylation of chitin using acetic anhydride in an ionic liquid solvent, AMIMBr, was performed (Figure 6) [30]. Prior to acetylation, chitin was dissolved with AMIMBr $(2.0 \mathrm{wt} \%)$ by heating the mixture at $100^{\circ} \mathrm{C}$ for $24 \mathrm{~h}$ with stirring. Then, the 5 - 20 equiv. of acetic anhydride for a repeating unit was added to the solution and the mixture was heated at $60^{\circ} \mathrm{C}-100^{\circ} \mathrm{C}$ for $24 \mathrm{~h}$ with stirring. The products were isolated as a fraction insoluble in methanol and the DS values of the products were estimated by comparison of the intensities of the two carbonyl absorptions due to amido I (ca. $1658 \mathrm{~cm}^{-1}$ ) and ester (ca. $1745 \mathrm{~cm}^{-1}$ )

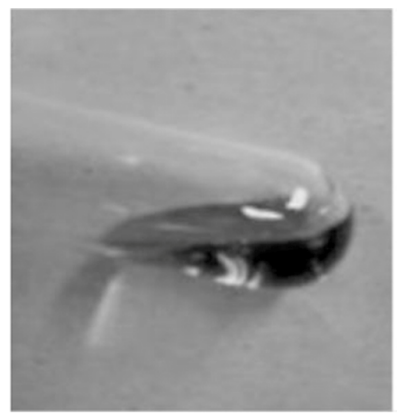

(a)

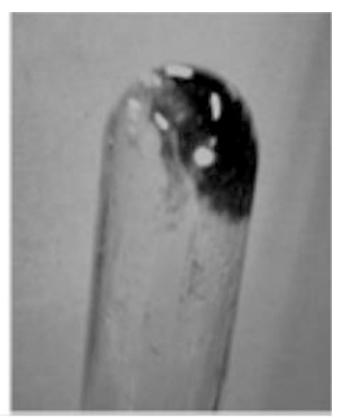

(b)
Figure 5. Photographs of $4.8 \mathrm{wt} \%$ (a) and $6.5 \mathrm{wt} \%$ (b) chitin with AMIMBr.

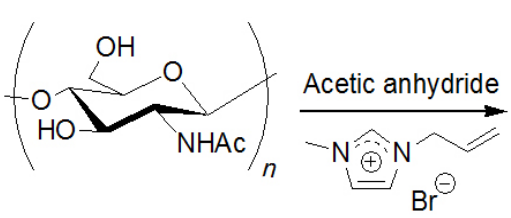

$\mathrm{AMIMBr}$

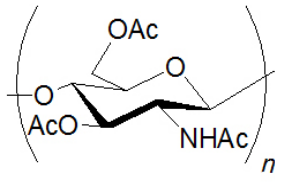

$A c=-\underset{0}{\mathrm{C}}-\mathrm{CH}_{3}$
Figure 6. Acetylation of chitin using acetic anhydride in AMIMBr. 
in the IR spectra (Figure 7). No acetylation took place under the conditions using 5 equiv. of acetic anhydride at $60^{\circ} \mathrm{C}$. While the DS values increased under the conditions using larger equiv. of acetic anhydride at higher reaction temperatures. The highest DS value (1.86) was obtained when the reaction was carried out using 20 equiv. of acetic anhydride at $80^{\circ} \mathrm{C}$.

Because the products with high DS, which were obtained by the reaction using 20 equiv. of acetic anhydride, were soluble in DMSO, the structures of these products were further confirmed by the ${ }^{1} \mathrm{H}$ NMR analysis measured in DMSO- $d_{6}$. On the basis of the integrated ratios of the signals due to the acetyl protons to the signal due to the anomeric protons, the DS values were calculated, which were in good agreement with those determined by the IR spectra. The all the above results indicated that $\mathrm{AMIMBr}$ was the powerful media for the efficient derivatization of chitin.

\section{Preparation of Nanofiber Films from Chitin Ion Gel with Ionic Liquid}

The author has reported that chitin nanofiber films were formed by regeneration from the aforementioned ion gels with AMIMBr using methanol, followed by filtration (Figure 8, Route A) [46]. First, chitin was swollen with $\mathrm{AMIMBr}$ according to the procedure as aforementioned to give the chitin ion gels with AMIMBr $(9.1 \mathrm{wt} \%-10.7$ $w t \%)$. It was found that chitin dispersions were obtained when the gels were immersed in methanol at room temperature for $24 \mathrm{~h}$ to slowly regenerate chitin, followed by sonication. The resulting dispersion was diluted with methanol, which was subjected to the SEM measure-

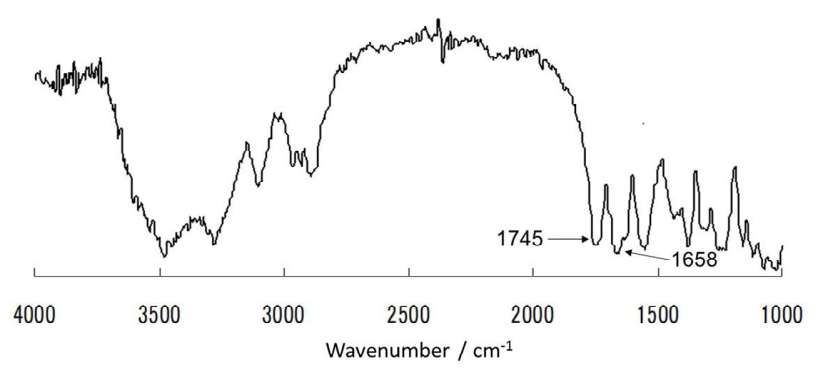

Figure 7. IR spectrum of acetylated chitin obtained using 20 equiv. of acetic anhydride at $60^{\circ} \mathrm{C}$ (DS value; 1.79).

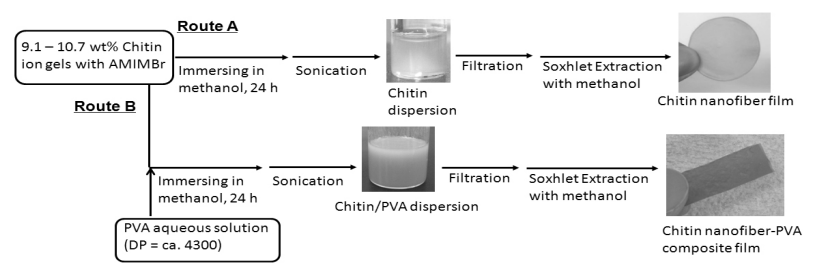

Figure 8. Procedures for the preparation of chitin dispersion/nanofiber film (Route A) and chitin nanofiber-PVA composite film (Route B). ment. The morphology of nanofibers with ca. $20 \mathrm{~nm}-60$ $\mathrm{nm}$ in width and several hundred nanometers in length was observed in the SEM image of the sample from the dispersion (Figure 9(a)), indicating the formation of the self-assembled chitin nanofibers by the above regeneration approach from the ion gel according to the bottomup process. When the dispersion was filtered, the residue formed a film, which was further purified by Soxhlet extraction with methanol. The SEM image of the resulting film was also measured to confirm the nanoscaled morphology of chitin, which showed the pattern of highly entangled nanofibers (Figure 9(b)). This suggested that such entangled structure of the nanofibers contributed to formability of the film. The XRD pattern of the chitin nanofiber film mainly showed the diffraction peaks corresponding to crystalline structure of $\alpha$-chitin and is in good agreement with that of an original chitin powder. The result indicated that the crystalline structure of $\alpha$ chitin was reconstructed by the above regeneration procedure during the formation of the nanofibers.

As one of the possible applications of the present chitin nanofiber film, the preparation of the chitin nanofiberpoly(vinyl alcohol) (PVA) composite films was investigated (Figure 8, Route B) [46]. First, the $9.1 \mathrm{wt} \%$ chitin ion gel with AMIMBr was prepared according to the aforementioned procedure and a solution of PVA (DP = ca. 4300) in a small amount of hot water was added to the gel (the feed weight ratio of chitin to PVA $=1: 0.30$ ). Then, the co-regeneration using methanol was conducted, followed by filtration and Soxhlet extraction with methanol same as the aforementioned procedure to produce the chitin nanofiber-PVA composite film. It was confirmed that a small amount of AMIMBr was remained in the composite. The SEM image of the composite showed that the nanofiber-like morphology was maintained and PVA components probably filled in spaces among the fibers (Figure 9(c)), indicating relative immiscibility of chitin and PVA in the composite. Indeed, the DSC profile of the composite film exhibited an endothermic peak attributed to the melting point of PVA, suggesting some immiscibility of PVA toward chitin in the composite. However, the melting point peak of PVA in the composite film was broadened, indicating that the crystallinity of PVA decreased in the composite film. The DSC result suggested that chitin and PVA might be partially misci-
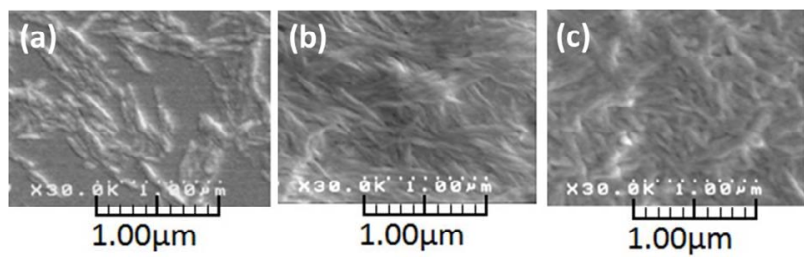

Figure 9. SEM images of chitin dispersion (a), chitin nanofiber film (b), and chitin nonofiber-PVA composite film (c). 
ble at the interfacial area between the two polymers in the composite film by the formation of hydrogen bonding between them or by the presence of a small amount of AMIMBr.

\section{Conclusion}

This article reviewed the dissolution, derivatization, and nanomaterial processing of chitin using the ionic liquid, AMIMBr. Because the author found that AMIMBr dissolved chitin in the concentrations up to $4.8 \mathrm{wt} \%$ by heating and further the chitin ion gels were obtained from the mixture of the higher amounts of chitin with AMIMBr, acetylation of chitin using acetic anhydride was performed in the AMIMBr solvent to give the acetylated chitins with the high DS values. Chitin-based nanomaterials such as chitin nanofibers and nanocomposites with synthetic polymer were also fabricated using AMIMBr. Immersing the ion gel in methanol and subsequent sonication gave the chitin dispersion. The SEM image of the dispersion showed the formation of the self-assembled chitin nanofibers. Then, filtration of the dispersion was carried out to give the chitin nanofiber film. The composite film of the chitin nanofibers with PVA was prepared by a similar procedure as that for the chitin nanofiber film. The present methods using the ionic liquid, AMIMBr, provide new chitin-based functional and composite materials which have a highly potential to apply to practical material research filed in the future. Finally, the author would like to state that this review has especially presented to the readers how the ionic liquid media are useful for new approaches in the chitin research field, which will be increasingly developed with attracting much attention on the further technological interests in the efficient use of chitin as the abundant biomass resource.

\section{Acknowledgements}

The author is indebted to the co-workers, whose names are found in references from his papers, for their enthusiastic collaborations.

\section{REFERENCES}

[1] T. Welton, "Room-Temperature Ionic Liquids. Solvents for Synthesis and Catalysis," Chemical Reviews, Vol. 99, No. 8, 1999, pp. 2071-2084. doi:10.1021/cr980032t

[2] P. Wasserscheid and W. Keim, "Ionic Liquids: New 'Solutions' for Transition Metal Catalysis," Angewandte Chemie International Edition, Vol. 39, No. 21, 2000, pp. 3772-3789. doi:10.1002/1521-3773(20001103)39:21<3772::AID-AN IE3772>3.0.CO;2-5

[3] N. V. Plechkova and K. R. Seddon, "Applications of Ionic Liquids in the Chemical Industry," Chemical Society
Reviews, Vol. 37, No. 1, 2008, pp. 123-150. doi: $10.1039 / \mathrm{b} 006677 \mathrm{i}$

[4] O. A. E. Seoud, A. Koschella, L. C. Fidale, S. Dorn and T. Heinze, "Applications of Ionic Liquids in Carbohydrate Chemistry: A Windows of Opportunities," Biomacromolecules, Vol. 8, No. 9, 2007, pp. 2629-2648. doi:10.1021/bm070062i

[5] C. Schuerch, "Polysaccharides," In: H. F. Mark, N. Bilkales and C. G. Overberger, Eds., Encyclopedia of Polymer Science and Engineering, 2nd Edition, John Wiley \& Sons, New York, 1986, Vol. 13, pp. 87-162.

[6] D. Klemm, B. Heublein, H.-P. Fink and A. Bohn, "Cellulose: Fascinating Biopolymer and Sustainable Raw mMaterial," Angewandte Chemie International Edition, Vol. 44, No. 22, 2005, pp. 3358-3393. doi:10.1002/anie.200460587

[7] M. Rinaudo, "Chitin and Chitosan: Properties and Applications," Progress in Polymer Science, Vol. 31, No. 7, 2006, pp. 603-632. doi:10.1016/j.progpolymsci.2006.06.001

[8] K. Kurita, "Chitin and Chitosan: Functional Biopolymers from Marine Crustaceans," Marine Biotechnology, Vol. 8, No. 3, 2006, pp. 203-226. doi:10.1007/s10126-005-0097-5

[9] C. K. S. Pillai, W. Paul and C. P. Sharma "Chitin and Chitosan Polymers: Chemistry, Solubility and Fiber Formation," Progress in Polymer Science, Vol. 34, No. 7, 2009, pp. 641-678. doi:10.1016/i.progpolymsci.2009.04.001

[10] R. A. A. Muzzarelli, "Chitin Nanostructures in Living Organisms," In: S. N. Gupta, Ed., Chitin Formation and Diagenesis, Springer, New York, 2011.

[11] D. Raabe, P. Romano, C. Sachs, H. Fabritius, A. Al-Sawalmih, S. B. Yi, G. Servos and H. G. Hartwig, "Microstructure and Crystallographic Texture of the Chitin-Protein Network in the Biological Composite Material of the Exoskeleton of the Lobster Homarus Americanus," Materials Science and Engineering A-Structural Materials Properties Microstructure and Processing, Vol. 421, No. 1-2, 2006, pp. 143-153.

[12] P. Y. Chen, A. Y. M. Lin, J. McKittrick and M. A. Meyers, "Structure and Mechanical Properties of Crab Exoskeletons," Acta Biomaterialia, Vol. 4, No. 3, 2008, pp. 587-596. doi:10.1016/j.actbio.2007.12.010

[13] R. Minke and J. Blackwell, "The Structure of $\alpha$-Chitin," Journal of Molecular Biology, Vol. 120, No. 2, 1978, pp. 167-181. doi:10.1016/0022-2836(78)90063-3

[14] K. H. Gardner and J. Blackwell, "Refinement of the Structure of $\beta$-Chitin," Biopolymers, Vol. 14, No. 8, 1975, pp. 1581-1595. doi:10.1002/bip.1975.360140804

[15] R. P. Swatloski, S. K. Spear, J. D. Holbrey and R. D. Rogers, "Dissolution of Cellulose with Ionic Liquids," Journal of the American Chemical Society, Vol. 124, No. 18, 2002, pp. 4974-4975. doi:10.1021/ja025790m

[16] T. Liebert and T. Heinze, "Interaction of Ionic Liquids with Polysaccharides 5. Solvents and Reaction Media for the Modification of Cellulose," BioResources, Vol. 3, No. 2, 2008, pp. 576-601. 
[17] L. Feng and Z. I. Chen, "Research Progress on Dissolution and Functional Modification of Cellulose in Ionic Liquids," Journal of Molecular Liquids, Vol. 142, No. 13, 2008, pp. 1-5. doi:10.1016/i.molliq.2008.06.007

[18] A. Pinkert, K. N. Marsh, S. Pang and M. P. Staiger, "Ionic Liquids and their Interaction with Cellulose," Chemical Reviews, Vol. 109, No. 12, 2009, pp. 6712-6728. doi:10.1021/cr9001947

[19] M. E. Zakrzewska, E. B. Lukasik and R. B. Lukasik, "Solubility of Carbohydrates in Ionic Liquids," Energy \& Fuels, Vol. 24, No. 2, 2010, pp. 737-745. doi:10.1021/ef901215m

[20] S. Yamazaki, A. Takegawa, Y. Kaneko, J. Kadokawa, M. Yamagata and M. Ishikawa, "An Acidic Cellulose-Chitin Hybrid Gel as Novel Electrolyte for an Electric Double Layer Capacitor," Electrochemistry Communications, Vol. 11, No. 1, 2009, pp. 68-70. doi:10.1016/j.elecom.2008.10.039

[21] K. Prasad, M. Murakami, Y. Kaneko, A. Takada, Y. Nakamura and J. Kadokawa, "Weak Gel of Chitin with Ionic Liquid, 1-Allyl-3-Methylimidazolium Bromide," International Journal of Biological Macromolecules, Vol. 45, No. 3, 2009, pp. 221-225. doi:10.1016/j.ijbiomac.2009.05.004

[22] Y. Wu, T. Sasaki, S. Irie and K. Sakurai, "A Novel Biomass-Ionic Liquid Platform for the Utilization of Native Chitin," Polymer, Vol. 49, No. 9, 2008, pp. 2321-2327. doi:10.1016/j.polymer.2008.03.027

[23] Y. Qin, X. Lu, N. Sun and R. D. Rogers, "Dissolution or Extraction of Crustacean Shells Using Ionic Liquids to Obtain High Molecular Weight Purified Chitin and Direct Production of Chitin Films and Fibers," Green Chemistry, Vol. 12, No. 6, 2010, pp. 968-971. doi:10.1039/c003583a

[24] W. T. Wang, J. Zhu, X. L. Wang, Y. Huang and Y. Z. Wang, "Dissolution Behavior of Chitin in Ionic Liquids," Journal of Macromolecular Science, Part B Physics, Vol. 49, No. 3, 2010, pp. 528-541. doi:10.1080/00222341003595634

[25] R. A. A. Muzzarelli, "Biomedical Exploitation of Chitin and Chitosan via Mechano-Chemical Disassembly, Electrospinning, Dissolution in Imidazolium Ionic Liquids, and Supercritical Drying," Marine Drugs, Vol. 9, No. 9, 2011, pp. 1510-1533. doi:10.3390/md9091510

[26] M. M. Jaworska, T. Kozlecki and A. Gorak, "Review of the Application of Ionic Liquids as Solvents for Chitin," Journal of Polymer Engineering, Vol. 32, No. 2, 2012, pp. 67-69. doi:10.1515/polyeng-2011-0145

[27] A. M. Bochek, A. A. Muravev, N. P. Novoselov, M. Zaborski, N. M. Zabivalova, V. A. Petrova, E. N. Vlasova, B. Z. Volchek and V. K. Lavrentev, "Specific Features of Cellulose and Chitin Dissolution in Ionic Liquids of Varied Structure and the Structural Organization of Regenerated Polysaccharides," Russian Journal of Applied Chemistry, Vol. 85, No. 11, 2012, pp. 1718-1725. doi:10.1134/S1070427212110158

[28] K. Kurita, "Controlled Functionalization of the Polysaccharide Chitin," Progress in Polymer Science, Vol. 26, No. 9, 2001, pp. 1921-1971. doi:10.1016/S0079-6700(01)00007-7
[29] M. Morimoto, H. Saimoto and Y. Shigemasa, "Control of Functions of $\alpha$-Chitin and Chitosan by Chemical Modification," Trends in Glycoscience and Glycotechnology, Vol. 14, No. 78, 2002, pp. 205-222. doi:10.4052/tigg. 14.205

[30] S. Mine, H. Izawa, Y. Kaneko and J. Kadokawa, "Acetylation of Chitin in Ionic Liquids," Carbohydrate Reserach, Vol. 344, No. 16, 2009, pp. 2263-2265. doi:10.1016/j.carres.2009.08.004

[31] J. B. Zeng, Y. S. He, S. L. Li and Y. Z. Wang, "Chitin Whiskers: A Overview," Biomacromolecules, Vol. 13, No. 1, 2012, pp. 1-11. doi:10.1021/bm201564a

[32] S. Ifuku and H. Saimoto, "Chitin Nanofibers: Preparations, Modifications, and Applications," Nanoscale, Vol. 4, No. 11, 2012, pp. 3308-3318. doi: $10.1039 / \mathrm{c} 2 \mathrm{nr} 30383 \mathrm{c}$

[33] S. Ifuku, "Preparation of Chitin Nanofibers from Crab Shell and Their Applications," Kobunshi Ronbunshu, Vol. 69, No. 8, 2012, pp. 460-467. doi:10.1295/koron.69.460

[34] J. F. Revol and R. H. Marchessault, "In-Vitro Chiral Nematic Ordering of Chitin Crystallites," International Journal of Biological Macromolecules, Vol. 15, No. 6, 1993, pp. 329-335. doi:10.1016/0141-8130(93)90049-R

[35] J. Li, J. F. Revol, E. Naranjo and R. H. Marchessault, "Effect of Electrostatic Interaction on Phase Separation of Chitin Crystallite Suspensions," International Journal of Biological Macromolecules, Vol. 18, No. 3, 1996, pp. 177187. doi:10.1016/0141-8130(95)01066-1

[36] J. Li, J. F. Revol and R. H. Marchessault, "Effect of Degree of Deacetylation of $\alpha$-Chitin on the Properties of Chitin Crystallites," Journal of Applied Polymer Science, Vol. 65, No. 2, 1997, pp. 373-380.

doi:10.1002/(SICI)1097-4628(19970711)65:2<373::AIDAPP18>3.0.CO;2-0

[37] J. D. Goodrich and W. T. Winter, " $\alpha$-Chitin Nanocrystals Prepared from Shrimp Shells and Their Specific Sur- face Area Measurement," Biomacromolecules, Vol. 8, No. 1, 2007, pp. 252-257. doi:10.1021/bm0603589

[38] Y. Fan, T. Saito and A. Isogai, "Chitin Nanocrystals Prepared by TEMPO-Mediated Oxidation of $\alpha$-Chitin," Biomacromolecules, Vol. 9, No. 1, 2008, pp. 192-198. doi:10.1021/bm700966g

[39] Y. Fan, T. Saito and A. Isogai, "TEMPO-Mediated Oxidation of $\alpha$-Chitin to Prepare Individual Nanofibers," Carbohydrate Polymers, Vol. 77, No. 4, 2009, pp. 832-838. doi:10.1016/j.carbpol.2009.03.008

[40] S. Ifuku, M. Nogi, K. Abe, M. Yoshioka, M. Morimoto, H. Saimoto and H. Yano, "Preparation of Chitin Nanofibers with a Uniform Width as $\alpha$-Chitin from Crab Shells," Biomacromolecules, Vol. 10, No. 6, 2009, pp. 1584-1588. doi:10.1021/bm900163d

[41] S. Ifuku, M. Nogi, M. Yoshioka, M. Morimoto, H. Yano and H. Saimoto, "Fibrillation of Dried Chitin into 10-20 nm Nanofibers by a Simple Grinding Method under Acidic Conditions," Carbohydrate Polymers, Vol. 81, No. 1, 2010, pp. 134-139. doi:10.1016/j.carbpol.2010.02.006

[42] J. D. Schiffman, L. A. Stulga and C. L. Schauer, "Chitin and Chitosan: Transformations Due to the Electrospin- 
ning Process," Polymer Engineering and Science, Vol. 49, No. 10, 2009, pp. 1918-1928.

doi:10.1002/pen.21434

[43] R. Jayakumar, M. Prabaharan, S. V. Nair and H. Tamura, "Novel Chitin and Chitosan Nanofibers in Biomedical Applications," Biotechnology Advances, Vol. 28, No. 1, 2010, pp. 142-150. doi:10.1016/j.biotechadv.2009.11.001

[44] C. Zhong, A. Cooper, A. Kapetanovic, Z. Fang, M. Zhang and M. Rolandi, "A Facile Bottom-Up Route to Self-Assembled Biogenic Nanofibers," Soft Matter, Vol. 6, No. 21, 2010, pp. 5298-5301. doi:10.1039/c0sm00450b

[45] C. Zhong, A. Kapetanovic, Y. Deng and M. Rolandi, “A Chitin Nanofiber Ink for Airbrushing, Replica Molding, and Microcontact Printing of Self-Assembled Macro-, Micro-, and Nanostructures," Advanced Materials, Vol. 23, No. 41, 2011, pp. 4776-4781.

doi:10.1002/adma.201102639
[46] J. Kadokawa, A. Takegawa, S. Mine and K. Prasad, "Preparation of Chitin Nanowhiskers Using an Ionic Liquid and Their Composite Materials with Poly(Viny Alcohol)," Carbohydrate Polymers, Vol. 84, No. 4, 2011, pp. 1408-1412. doi:10.1016/i.carbpol.2011.01.049

[47] Y. S. Vygodskii, E. L. Lozinskaya and A. S. Shaplov, "Ionic Liquids as Novel Reaction Media for the Synthesis of Condensation Polymers," Macromolecular Rapid Communications, Vol. 23, No. 12, 2002, pp. 676-680. doi:10.1002/1521-3927(20020801)23:12<676::AID-MA RC676>3.0.CO;2-2

[48] K. Kaifu, N. Nishi and T. Komai, "Preparation of Hexanoyl, Decanoyl, and Dodecanoylchitin," Journal of Polymer Science: Polymer Chemistry Edition, Vol. 19, No. 9, 1981, pp. 2361-2363. doi:10.1002/pol.1981.170190921 